\title{
Anomalous aortic origin of a coronary artery: 2020 year in review
}

Anusha Jegatheeswaran, MD, PhD, FRCSC, ${ }^{\mathrm{a}}$ and Bahaaldin Alsoufi, $\mathrm{MD}^{\mathrm{b}}$

While at first, managing patients with anomalous aortic origin of a coronary artery (AAOCA) may seem straightforward, in reality it involves a nuanced understanding of the ever-evolving literature in the field. The primary conundrum that clinicians face is determining which patients require repair, because their risk of sudden cardiac death is greater than the risks of surgery. It is difficult to determine the answer to this question because we do not know the true prevalence of this lesion in the general population, and as a result we do not know the risk of ischemia and sudden cardiac death. Currently, the management of patients often occurs at the discretion of cardiologists and surgeons who have a varying perception of how to interpret the literature and the complexity of a procedure that was once thought to be benign.

The guidelines also have evolved. Although it was initially recommended that all patients with left AAOCA and those with right AAOCA who have ischemia undergo surgery, the latest 2018 American College of Cardiology/ American Heart Association guidelines for the management of adults with congenital heart disease recommend that all patients with symptoms or ischemia during diagnostic testing undergo repair (Class I); however, for patients with left AAOCA who do not meet this criteria, surgical intervention is now only a Class IIa recommendation, which decreases to IIb in right AAOCA, unless patients have ventricular arrhythmias. ${ }^{1}$ As such, the purpose of this review is to highlight some of the key publications in the last year and provide our readers with a current understanding of how to evaluate and manage these patients.

\section{SURGICAL TECHNIQUES}

Jegatheeswaran and colleagues ${ }^{2}$ reviewed the surgical outcomes of 395 surgical patients in a cohort of 682 patients from 45 North American centers in the Congenital Heart Surgeons' Society cohort. They found that the most

\footnotetext{
From the ${ }^{\text {aDivision }}$ of Cardiovascular Surgery, Department of Surgery, Hospital for Sick Children, University of Toronto, Toronto, Ontario, Canada; and ${ }^{\mathrm{b}}$ Department of Cardiovascular and Thoracic Surgery, Norton Children's Hospital, University of Louisville School of Medicine, Louisville, Ky.

Received for publication April 12, 2021; revisions received April 12, 2021; accepted for publication April 15, 2021; available ahead of print April 24, 2021.

Address for reprints: Anusha Jegatheeswaran, MD, PhD, FRCSC, Hospital for Sick Children, 555 University Ave, Toronto, ON, M5G 1X8, Canada (E-mail: anusha. jegatheeswaran@utoronto.ca).

J Thorac Cardiovasc Surg 2021;162:353-9 0022-5223/\$36.00

Copyright (c) 2021 Published by Elsevier Inc. on behalf of The American Association for Thoracic Surgery

https://doi.org/10.1016/j.jtcvs.2021.04.048
}

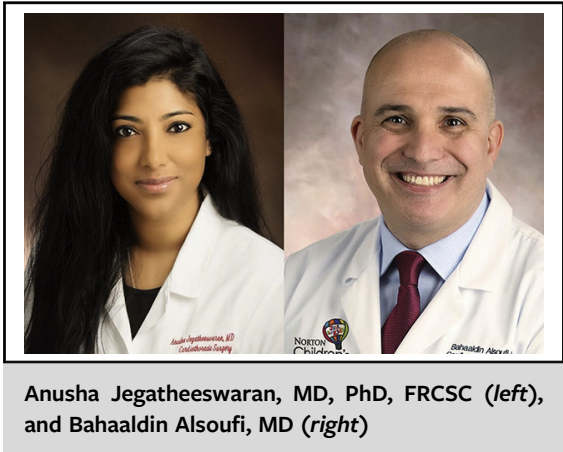

CENTRAL MESSAGE

Many unknowns remain

regarding AAOCA. However, our

knowledge of new surgical pro-

cedures, outcomes, and the util-

ity of advanced techniques for

imaging and risk stratification

continues to evolve.

commonly used repair strategies were isolated unroofing $(87 \%)$, unroofing with commissural manipulation $(25 \%)$, patch ostioplasty $(6 \%)$, reimplantation $(6 \%)$, and pulmonary artery translocation $(6 \%)$, followed by other strategies. Of note, intimal tacking was used in $74 \%$ of patients and commissural manipulation was performed in $26 \%$ of patients. It should be noted that these strategies each only address 1 or 2 anatomic issues and can only be used interchangeably in select situations.

The latest thinking is that all abnormal components of an anomalous vessel must be addressed to bring the coronary as close as possible to having a normal anatomy. This means that any issues related to the ostium (ie, stenosis or slit-like origin) and course (ie, an acute take-off and intramural or interarterial course) must be addressed during repair, in addition to ensuring the anomalous vessel is relocated to the appropriate sinus. This is in contrast to thinking that simply unroofing an intramural course is adequate if the vessel remains interarterial or is still not in the appropriate sinus. Gaillard and colleagues ${ }^{3}$ report the results of 35 patients (15 left and 20 right AAOCAs) who underwent anatomic repair in their cohort of 61 patients. Although 
there were no early or late postoperative mortalities and all patients within this group were free from ischemia at last follow-up, 3 symptomatic patients had acute postoperative events (1 translocation, 1 septal release/reimplantation, and 1 anatomic repair). Mean follow-up was 38 months (range, 1-15 years). With respect to late results, 2 patients with right AAOCA required angioplasties, 1 with stenting who ultimately underwent coronary artery bypass grafting for in-stent thrombosis. Three asymptomatic patch aneurysms were also found in patients who received anatomic repair using long saphenous vein patches, one of which was operated on but found to have no sign of rupture or infection, preventing operation in the other 2 patients. At latest follow-up, only 1 patient was symptomatic. It should be noted that although surgeons use multiple different patch materials during coronary repair, we still do not know which has the best durability and outcomes. ${ }^{4,5}$

This year also brought additional data regarding novel surgical solutions for intraconal/intraseptal anomalous coronaries. Although these lesions originally were largely thought to be benign, with the use of aggressive strategies for testing, including both fractional flow reserve and intravascular ultrasound, ischemia has been more clearly documented in these patients, leading to the requirement for repair. ${ }^{6}$ Najm and colleagues ${ }^{7}$ described the results of their novel technique for repair of these left AAOCAs in 7 patients. In their technique, they describe opening the right ventricular outflow tract below the pulmonary valve, dividing the posterior wall, and dissecting the right ventricular outflow tract muscles over the left main coronary artery until the bifurcation. This is followed by placement of an anteriorly tapered rectangular patch of fresh autologous pericardium in a rectangular shape to bridge the gap (Figure 1). With a median follow-up of 9 months (range, 0.48-12 months), there were no mortalities or major complications. Doan and colleagues ${ }^{8}$ reported the use of a myotomy over the intraseptal vessel after a transverse infundibular ventriculotomy, and Gaillard and colleagues ${ }^{3}$ reported 5 patients who underwent septal release (Figure 2).

\section{SURGICAL OUTCOMES}

Surgical repair of AAOCA was once thought to be a straightforward procedure with minimal morbidity and mortality, but this notion has been challenged. Jegatheeswaran and colleagues ${ }^{2}$ evaluated the surgical outcomes of 395 patients in the Congenital Heart Surgeons' Society cohort with a focus on the adverse outcomes after repair. They reviewed the surgical management in patients aged 30 years or less. The median age at surgery was 13.3 years (interquartile range, 9.9-15.5), and median follow-up in this cohort was 2.8 years (interquartile range, 1.1-5.0). Mortality was low with only 4 deaths ( $1 \%$ ) (3 elective, 1 urgent) within 30 days of surgery, but there was a surprisingly high composite risk of adverse events after repair. Of those who died, 2 patients were asymptomatic preoperatively. Adverse outcomes included 3\% coronary-related reoperations (15 reoperations in 13 patients), $8 \%$ new mild or more aortic insufficiency $(\mathrm{n}=27)$ or $2 \%$ new moderate or more aortic insufficiency $(n=7)$ in those evaluated before and after repair, 2\% new abnormal ejection fraction $(n=6)$, and $4 \%$ new positive postoperative ischemia at any time after repair $(n=14)$ or $2 \%$ if considered only on the basis of their last test $(n=8)$. Overall, when these events were reviewed together, the adverse event rate ranged from $7 \%$ to $13 \%$ based on whether the degree of aortic insufficiency considered was mild or more, or moderate or more, and whether the presence of postoperative ischemia was considered at any time or at the last test. They also calculated the adverse event rate for specific subgroups of interest. Subgroups that had higher risk than the entire cohort included those with preoperative ischemia (21\%-33\%), those with left AAOCA (14\%-20\%), those who underwent repair strategies other than unroofing $(12 \%-19 \%)$, and those who received unroofing with commissural manipulation (7\%-15\%). Subgroups who had lower risk than the entire cohort included those with right AAOCA $(4 \%-10 \%)$, those who underwent isolated unroofing $(5 \%-9 \%)$, and those without preoperative ischemia $(4 \%-9 \%)$ (Figure 3). Of note, freedom from mild aortic insufficiency differed in those who underwent commissural manipulation during repair versus those who did not $(85 \%$ vs $91 \%$ at 6 months, $83 \%$ vs $90 \%$ at 1 year, and $77 \%$ vs $88 \%$ at 3 years).

A large review of 167 adult patients with isolated AAOCA over a 2-year period from the Cleveland Clinic Foundation gave us our first major look at diagnosis, concomitant lesions, and surgical management in adult patients. $^{9}$ Jiang and colleagues ${ }^{10}$ reviewed 167 cases of AAOCA over a 2-year period that had the diagnosis code of congenital coronary anomaly. Among these patients, 96 had right AAOCA, 39 had AAOCA, 4 had left anterior descending AAOCA, 26 had circumflex AAOCA, and 2 had multiple anomalous vessels. They found that patients with right AAOCA were diagnosed significantly later than those with left AAOCA (55 vs 51 years, $P=.03$ ). Of these patients, $74 \%(124 / 167)$ were diagnosed secondary to evaluation of cardiac symptoms, followed by advanced imaging for cardiac or noncardiac surgery. Symptoms were most commonly chest pain $(63 \%)$ and dyspnea $(51 \%)$, with a small proportion who were asymptomatic $(8 \%)$. Surgical repair occurred as follows: A total of 61 patients $(31 \%)$ underwent open surgery, with the AAOCA addressed in 59\% (36/61). Concomitant procedures were performed in 39\% (14/36) of those in whom surgery addressed the anomalous vessel. During the follow-up period (median, 2.5 years), there were no mortalities and reoperations or cardiac events. The most common concomitant procedures included aortic valve surgery 

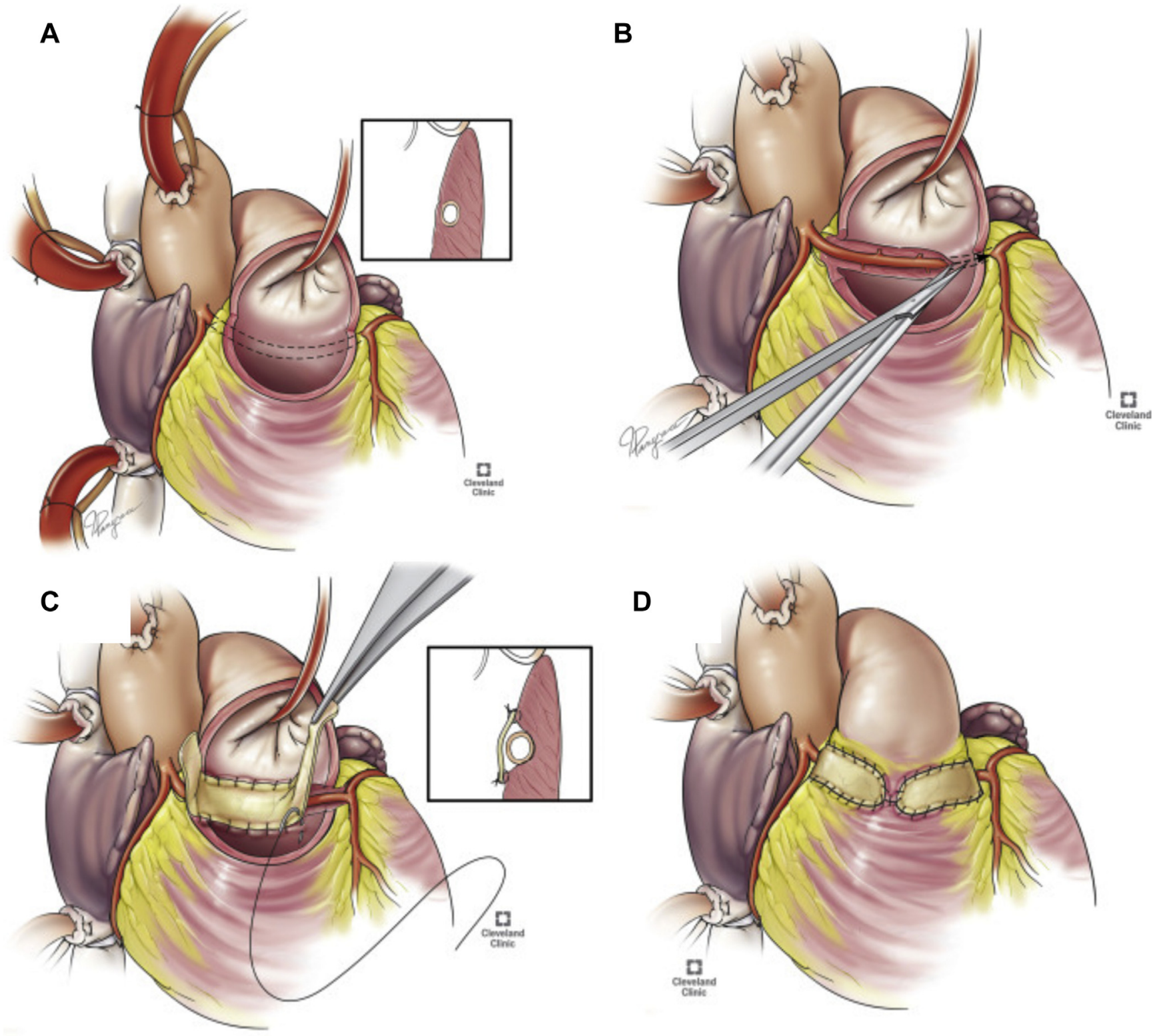

FIGURE 1. Transconal repair of left AAOCA with pericardial extension of right ventricular outflow tract. A, The right ventricular outflow tract is opened. The dotted lines indicate the planned incision line to unroof the coronary segment. The inset (right) shows the sagittal view of the anomalous coronary artery, surrounded by muscle. B, The coronary segment is unroofed throughout the entire intraseptal area. C, The coronary artery is bridged from the surrounding structures by a rectangular patch of autologous pericardium. Then inset (right) shows the unroofed segment with overlying pericardial patch. D, The completed repair, with the anterior right ventricular outflow tract closed with pericardium. Reproduced from Najm and Ahmad with permission from The Annals of Thoracic Surgery. ${ }^{21}$ AAOLCA, Anomalous aortic origin of a left coronary artery; RVOT, right ventricular outflow tract.

$(64 \%)$ and coronary artery bypass grafting $(21 \%)$, undoubtedly complicating the evaluation of the cause of symptoms. Of the 18 patients who underwent surgery primarily for their AAOCA with follow-up of more than 4 months, $13(72 \%)$ described improvement of their symptoms, and the rest did not report a change. Only 2 patients had the same modality of testing preoperatively and postoperatively. This is something that needs to change, because it is currently suggested that all patients undergo exercise stress testing at 3 months to clear them after surgery. ${ }^{11}$

\section{ADVANCED METHODS FOR DELINEATION OF ANATOMY AND RISK STRATIFICATION}

Heightened awareness of AAOCA and its potential role in sudden cardiac death have led to an increasing number of children and young adults diagnosed with AAOCA on screening studies without convincing symptoms of 

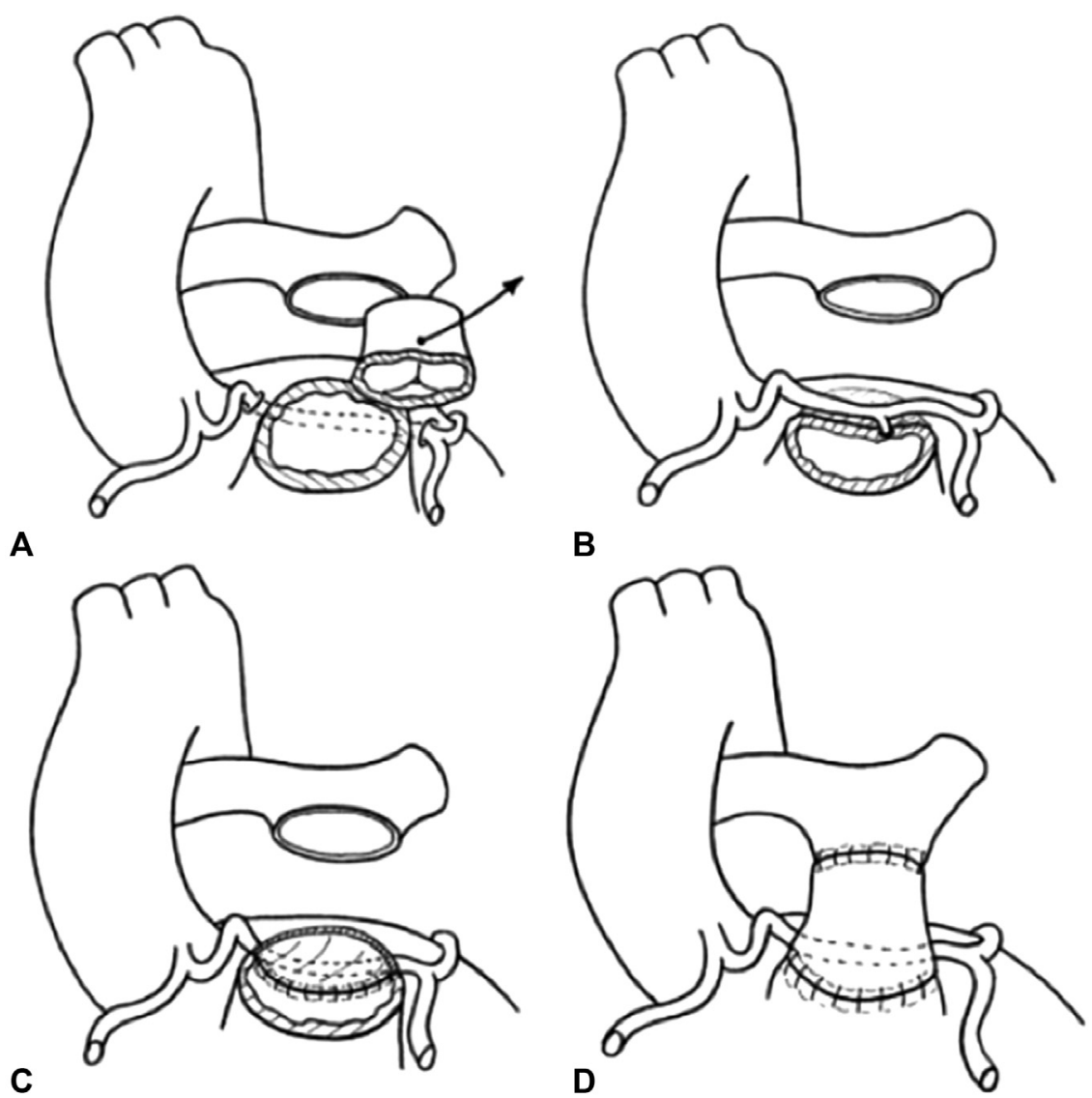

FIGURE 2. Septal release. A, Pulmonary root harvest, as performed for the Ross procedure. B, Division of the myocardial bridge to allow septal relief. $\mathrm{C}$ and D, Repositioning of the pulmonary trunk higher on the posterior aspect using a pericardial patch. Reproduced from Gaillard and colleagues with permission from the European Journal of Cardio-Thoracic Surgery. ${ }^{3}$

ischemia. A number of centers have developed diagnostic and treatment protocols to manage these patients, for example, the Texas Children's protocol highlighted in a recent review article by Molossi and Sachdeva. ${ }^{12}$ Given the persistent knowledge gaps in understanding the mechanism of ischemia and patients at risk, several articles have assessed the efficacy and accuracy of various advanced imaging methods in anatomic delineation and patient-specific risk stratification.

Krishnamurthy and colleagues ${ }^{13}$ assessed the accuracy of computed tomography angiography (CTA) in the identification of AAOCA and associated anatomic details, and compared CTA readings (3 blinded readers) with surgical findings in 25 patients. CTA was largely accurate in identification of AAOCA and intramural course and moderately accurate in identification of ostial location or lesions. The accuracies were the following: AAOCA presence $(100 \%)$, intramural course $(92 \%-98 \%)$, ostial stenosis $(84 \%-96 \%)$, and high ostial origin $(76 \%-82 \%)$.

Tang and colleagues ${ }^{14}$ assessed the value of noninvasive measurement of functional flow reserve (FFR) using CTA in 94 patients with right AAOCA. They compared those who had FFR 0.8 or less and greater than 0.8. Patients with FFR 0.80 or less had higher prevalence of typical $(29 \%$ vs $8 \%$ ) and atypical $(29 \%$ vs $7 \%)$ angina. Moreover, high-risk anatomic features (high take-off, ostial stenosis, long intramural course) were more prevalent in those with FFR 0.80 or less. They suggested that FFR measurement with CTA might have potential as a noninvasive tool for risk stratification. The same modality was also assessed by Ferrag and colleagues, ${ }^{15}$ again suggesting a potential role in patient-specific risk stratification. Although the study was interesting and potentially useful, limitations included the lack of noninvasive FFR validation against catheter-derived FFR and the validation of anatomic features against surgical findings.

Agrawal and colleagues ${ }^{16}$ examined the role of stress cardiovascular magnetic resonance (sCMR) as a noninvasive tool to evaluate myocardial perfusion in children with coronary anomalies (including but not only limited to AAOCA) and compared that with invasive FFR measurement (performed at baseline using dobutamine or regadenoson as provocative agents). FFR was considered abnormal if less than 0.8 in the affected coronary. The 2 modalities 


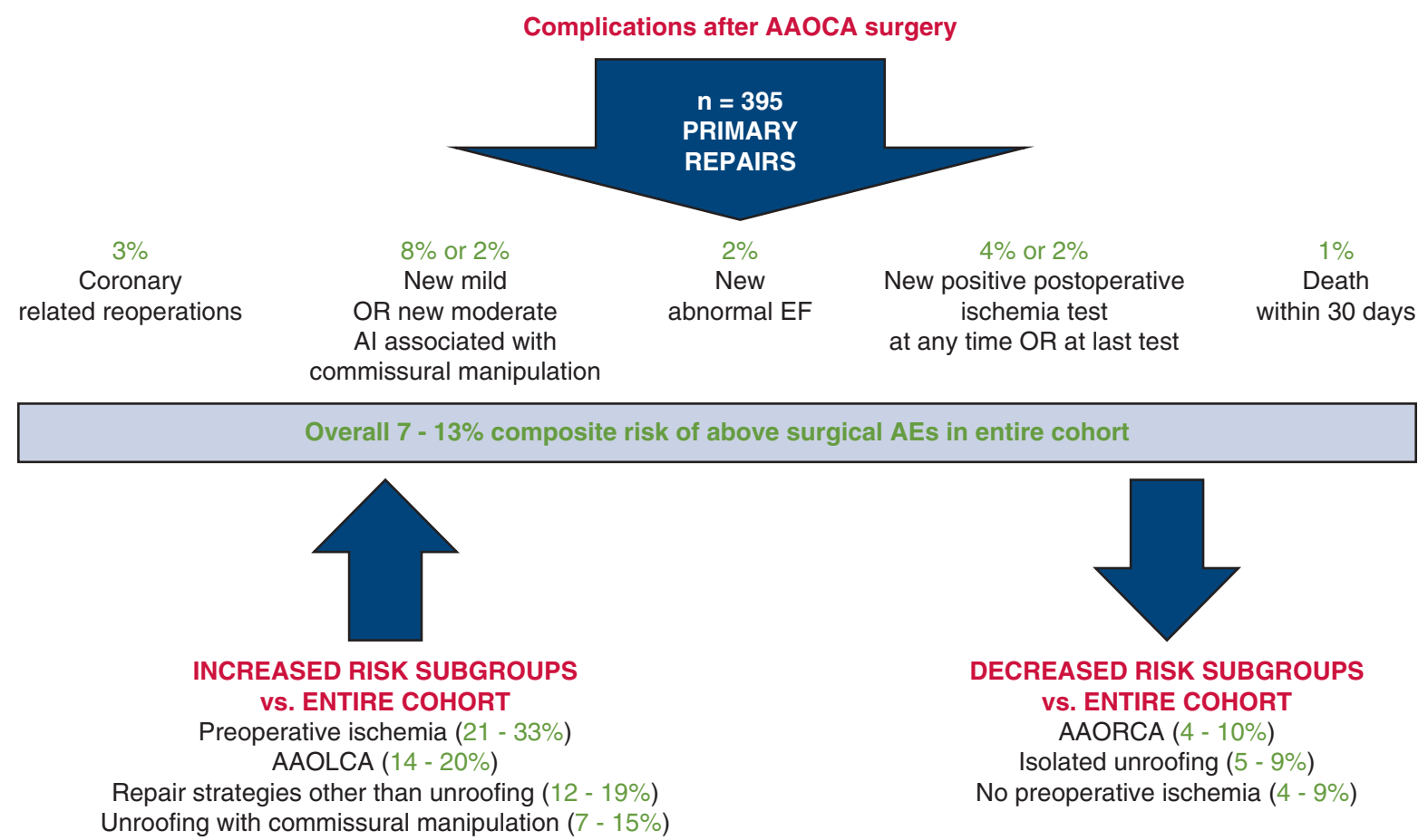

FIGURE 3. Primary findings related to the surgical risks of AAOCA repair. Ranges for surgical adverse events based on calculations using occurrence of new mild or new moderate aortic insufficiency associated with commissural manipulation and new postoperative ischemia based on any or last postoperative ischemia test. AAOCA, Anomalous aortic origin of a coronary artery; $A I$, aortic insufficiency; $E F$, ejection fraction; $A E$, adverse event; $A A O L C A$, anomalous aortic origin of a left coronary artery; AAORCA, anomalous aortic origin of a right coronary artery. Reproduced from Jegatheeswaran and colleagues with permission from the Journal of Thoracic and Cardiovascular Surgery. ${ }^{2}$

agreed in approximately $80 \%$ of patients especially if done with close time proximity, suggesting that sCMR may help in risk stratification and decision-making in AAOCA and myocardial bridges. Some studies examined the role of nuclear perfusion scans in the assessment of potential ischemia, but the reliability of this seems to vary among centers, with many favoring sCMR. ${ }^{12}$

In an attempt to quantify the pathological behavior of AAOCA and potentially help in patient-specific risk stratification, Lo Rito and colleagues ${ }^{17}$ performed computational modeling (finite element analysis) of CTA data (5 patients with right AAOCA and 5 normal controls). They examined simulated dynamic changes in coronary diameter during modeled loading conditions (increasing aortic pressure to 80,120 , and $180 \mathrm{~mm} \mathrm{Hg}$ to simulate exercise). They showed that right AAOCA was unable to expand its lumen in the intramural segment at loading conditions. The clinical relevance and validity of this model in real life remain to be determined. Another study by Razavi and colleagues ${ }^{18}$ assessed coronary wall sheer stress using computational flow dynamics models in 6 patients after surgical repair of AAOCA ( 2 of them also had preoperative models). Coronary wall shear stress usually normalized after unroofing. However, persistence of acute angle of origin continued to alter wall shear stress and affect coronary flow patterns.
Right and left coronary artery flows were also different. Again, the predictability of these models remains to be determined because they involve a small number of patients, and computational flow dynamics techniques have limited the ability to account for various factors such as compression of intramural segment by aortic elastic structures and the intercoronary pillar (both contributors to ischemia).

Several investigators examined the feasibility of transfer of morphologic characteristics of AAOCA from imaging to patient-specific 3-dimensional (3D) printed models. Farooqi and colleagues ${ }^{19}$ had 14 cardiac imagers and congenital surgeons review studies of 6 patients (echocardiogram, CTA, and 3D digital models). Participants accurately assessed AAOCA presence, type, and course on CTA and 3D models better than on echocardiogram. The 3D models were superior in the representation of ostial characteristics. Hatoum and colleagues ${ }^{20}$ had patient-specific $3 \mathrm{D}$ printed models for 3 patients with right AAOCA. The models were placed in the aortic position of a pulse duplicator, and FFR and coronary flow rate were measured from the aortic to the mediastinal segment of the anomalous right coronary artery and compared with controls with normal coronaries. In 2 patients with AAOCA and history of ischemia, there was a gradual FFR decrease from the ostium 
location $(\sim 1.0)$ to the distal intramural course $(0.48)$. In 1 patient with AAOCA and no history of ischemia and in those with normal coronaries, FFR for all locations did not decrease below 0.9. The decrease in FFR improved after repair. In addition, coronary flow rate decreased with increasing aortic pressure, but the difference was greater in the patients with AAOCA and a history of ischemia. This might explain the origin of ischemia and sudden death risk in these patients and might prove useful in risk stratification. However, these models are associated with several limitations, including a small number of patients, the inability to assess various anatomic features that could affect ischemia (eg, ostial stenosis, long intramural course), and not modeling pulmonary artery pressure.

\section{CONCLUSIONS}

Many unknowns remain regarding AAOCA. However, each year there is an evolution of our understanding, with continual advances in our knowledge of new surgical techniques, surgical outcomes, and the utility of advanced techniques for imaging and risk stratification.

\section{Conflict of Interest Statement}

The authors reported no conflicts of interest.

The Journal policy requires editors and reviewers to disclose conflicts of interest and to decline handling or reviewing manuscripts for which they may have a conflict of interest. The editors and reviewers of this article have no conflicts of interest.

\section{References}

1. Stout KK, Daniels CJ, Aboulhosn JA, Bozkurt B, Broberg CS, Colman JM, et al 2018 AHA/ACC guideline for the management of adults with congenital heart disease: executive summary: a report of the American College of Cardiology/ American Heart Association task force on clinical practice guidelines. J Am Coll Cardiol. 2019;73:1494-563.

2. Jegatheeswaran A, Devlin PJ, Williams WG, Brothers JA, Jacobs ML, DeCampli WM, et al. Outcomes after anomalous aortic origin of a coronary artery repair: a Congenital Heart Surgeons' Society Study. J Thorac Cardiovasc Surg. 2020;160:757-71.e755.

3. Gaillard M, Pontailler M, Danial P, Moreau de Bellaing A, Gaudin R, du PuyMontbrun L, et al. Anomalous aortic origin of coronary arteries: an alternative to the unroofing strategy. Eur J Cardiothorac Surg. 2020;58:975-82.

4. Jegatheeswaran A. Commentary: femoral artery homograft for coronary artery plasty-will it withstand the test of time? JCTVS Tech. 2020;4:237-8.

5. Mosca R, Chen D, Halpern D, Ma C, Feinberg J, Bhatla P, et al. Femoral artery homograft for coronary artery plasty following arterial switch operation. JCTVS Tech. 2020;4:232-4.
6. Doan TT, Zea-Vera R, Agrawal H, Mery CM, Masand P, ReavesO'Neal DL, et al. Myocardial ischemia in children with anomalous aortic origin of a coronary artery with intraseptal course. Circ Cardiovasc Interv. 2020;13:e008375.

7. Najm HK, Karamlou T, Ahmad M, Hassan S, Salam Y, Majdalany D, et al. Early outcomes of transconal repair of transseptal anomalous left coronary artery from right sinus. Ann Thorac Surg. March 21, 2021 [Epub ahead of print].

8. Doan TT, Molossi S, Qureshi AM, McKenzie ED. Intraseptal anomalous coronary artery with myocardial infarction: novel surgical approach. Ann Thorac Surg. 2020;110:e271-4.

9. Jegatheeswaran A, Devlin PJ, McCrindle BW, Williams WG, Jacobs ML, Blackstone EH, et al. Features associated with myocardial ischemia in anomalous aortic origin of a coronary artery: a Congenital Heart Surgeons' Society study. J Thorac Cardiovasc Surg. 2019;158:822-34.e823.

10. Jiang MX, Blackstone EH, Karamlou T, Ghobrial J, Brinza EK, Haupt MJ, et al. Anomalous aortic origin of a coronary artery in adults. Ann Thorac Surg. December 5, 2020 [Epub ahead of print].

11. Brothers JA, Frommelt MA, Jaquiss RDB, Myerburg RJ, Fraser CD Jr, Tweddell JS. Expert consensus guidelines: anomalous aortic origin of a coronary artery. J Thorac Cardiovasc Surg. 2017; 153:1440-57.

12. Molossi S, Sachdeva S. Anomalous coronary arteries: what is known and what still remains to be learned? Curr Opin Cardiol. 2020;35:42-51.

13. Krishnamurthy R, Masand PM, Jadhav SP, Molossi S, Zhang W, Agrawal HM, et al. Accuracy of computed tomography angiography and structured reporting of high-risk morphology in anomalous aortic origin of coronary artery: comparison with surgery. Pediatr Radiol. March 23, 2021 [Epub ahead of print].

14. Tang CX, Lu MJ, Schoepf JU, Tesche C, Bauer M, Nance J, et al. Coronary computed tomography angiography-derived fractional flow reserve in patients with anomalous origin of the right coronary artery from the left coronary sinus. Korean J Radiol. 2020;21:192-202.

15. Ferrag W, Scalbert F, Adjedj J, Dupouy P, Ou P, Juliard JM, et al. Role of FFR-CT for the evaluation of patients with anomalous aortic origin of coronary artery. JACC Cardiovasc Imaging. 2021;14:1074-6.

16. Agrawal H, Wilkinson JC, Noel CV, Qureshi AM, Masand PM, Mery CM, et al. Impaired myocardial perfusion on stress CMR correlates with invasive FFR in children with coronary anomalies. J Invasive Cardiol. 2021;33: E45-51.

17. Lo Rito M, Romarowski RM, Rosato A, Pica S, Secchi F, Giamberti A, et al. Anomalous aortic origin of coronary artery biomechanical modeling: toward clinical application. J Thorac Cardiovasc Surg. 2020 [In press].

18. Razavi A, Sachdeva S, Frommelt PC, LaDisa JF Jr. Patient-specific numerical analysis of coronary flow in children with intramural anomalous aortic origin of coronary arteries. Semin Thorac Cardiovasc Surg. 2021; 33:155-67.

19. Farooqi KM, Nees SN, Smerling J, Senapathi SH, Lorenzoni R, Pavlicova M, et al. Assessment of anomalous coronary arteries by imagers and surgeons: comparison of imaging modalities. Ann Thorac Surg. 2021;111:672-81.

20. Hatoum H, Krishnamurthy R, Parthasarathy J, Flemister DC, Krull CM, Walter BA, et al. Flow dynamics in anomalous aortic origin of a coronary artery in children: importance of the intramural segment. Semin Thorac Cardiovasc Surg. November 23, 2020 [Epub ahead of print].

21. Najm HK, Ahmad M. Transconal unroofing of anomalous left main coronary artery from right sinus with trans-septal course. Ann Thorac Surg. 2019;108: e383-6.

Key Words: AAOCA, coronary artery anomalies, unroofing of the coronary artery 


\section{Anomalous Aortic Origin of a Coronary Artery: Recent Articles From AATS Journals}
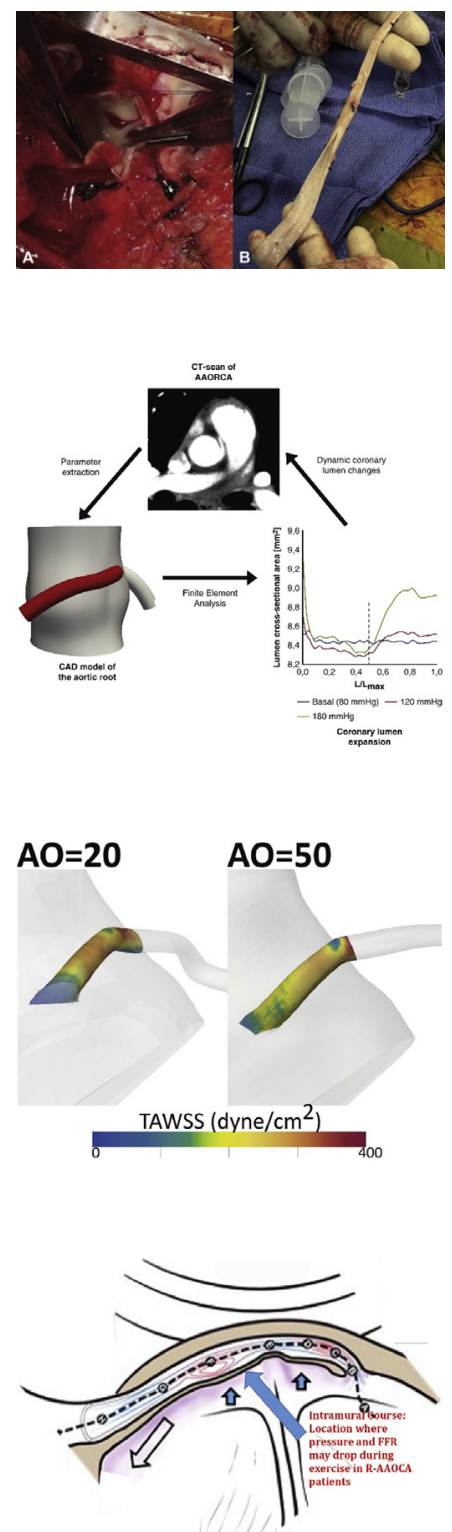

JTCVS TECHNIQUES: Femoral artery homograft for coronary artery plasty following arterial switch operation. Mosca R, Chen D, Halpern D, Ma C, Feinberg J, Bhatla P, Kumar TKS. J Thorac Cardiovasc Surg Tech. 2020;4:232-234

Commentary: A new option for patch material on coronary artery ostium plasty. Maeda K, Ryan KR. J Thorac Cardiovasc Surg Tech. 2020;4:235-236.

Commentary: Femoral artery homograft for coronary artery plasty —Will it withstand the test of time? Jegatheeswaran A. J Thorac Cardiovasc Surg Tech. 2020;4:237-238.

JTCVS: Anomalous aortic origin of coronary artery biomechanical modeling: Toward clinical application. Lo Rito M, Romarowski RM, Rosato A, Pica S, Secchi F, Giamberti A, Auricchio F, Frigiola A, Conti M. J Thorac Cardiovasc Surg. 2021;161(1):191-201.

Commentary: Modeling anomalous coronaries: Hard to predict the predictability of prediction. Woods RK. J Thorac Cardiovasc Surg. 2021;161(1):202.

Commentary: Are we there yet? Hancock Friesen CL, Hussain T. J Thorac Cardiovasc Surg. 2021;161(1):203-204.

Commentary: Anomalous coronary arteries and car crash testing. Miller JR, Eghtesady P. J Thorac Cardiovasc Surg. 2021;161(1):204-205.

STCVS: Patient-specific numerical analysis of coronary flow in children with intramural anomalous aortic origin of coronary arteries. Razavi A, Sachdeva S, Frommelt PC, LaDisa JF Jr. Semin Thorac Cardiovasc Surg. 2021;33(1):155-167.

Commentary: Computational fluid dynamics in anomalous coronaries: Moving from anecdote-based to data-based clinical decision-making. Hatoum $H$, Dasi $L P$, Krishnamurthy R, Molossi S, Mery CM. Semin Thorac Cardiovasc Surg. 2021;33(1):168-169. Commentary: Why stress it? Modeling of coronary wall shear stress and morphology of anomalous aortic origin of coronary artery may help define surgical strategy. Algahim MF. Semin Thorac Cardiovasc Surg. 2021;33(1):170-171.

STCVS: Flow dynamics in anomalous aortic origin of a coronary artery in children: Importance of the intramural segment. Hatoum H, Krishnamurthy R, Parthasarathy J, Flemister DC, Krull CM, Walter BA, Mery CM, Molossi S, Dasi LP. Semin Thorac Cardiovasc Surg. 2020 [In press]. 